\title{
Analysis of China's Primary Energy Structure and Emissions Reduction Targets by 2030 Based on Multiobjective Programming
}

\author{
Feng $\operatorname{Ren}^{1}$ and Long Xia ${ }^{2}$ \\ ${ }^{1}$ School of Business and Administration, North China Electric Power University, Baoding, Hebei Province 071003, China \\ ${ }^{2}$ School of Humanities and Social Sciences, North China Electric Power University, Baoding, Hebei Province 071003, China \\ Correspondence should be addressed to Feng Ren; renfeng2002@126.com
}

Received 6 December 2016; Revised 9 February 2017; Accepted 12 March 2017; Published 21 March 2017

Academic Editor: Aimé Lay-Ekuakille

Copyright ( $\odot 2017$ Feng Ren and Long Xia. This is an open access article distributed under the Creative Commons Attribution License, which permits unrestricted use, distribution, and reproduction in any medium, provided the original work is properly cited.

China's energy issues and carbon emissions have become important global concerns. The purpose of this paper is to analyze the fulfillment of China's commitment to carbon emissions reduction by 2030. We establish the Markov chain model to analyze the transition of primary energy structure and carbon emissions in China by 2030 without artificial intervention and build three multiobjective optimization models to analyze China's energy structure and emissions reduction targets by 2030 under three scenarios (scenario of energy structure optimization, scenario of energy intensity optimization, and scenario of energy structureintensity optimization). The findings show that the proportions of coal, oil, natural gas, and nonfossil energy will reach $17.89 \%$, $11.52 \%, 49.43 \%$, and $21.16 \%$, respectively; the total decreases in $\mathrm{CO}_{2}$ intensity reach $43.11 \%, 61.78 \%$, and $60.64 \%$, respectively; the $\mathrm{CO}_{2}$ emissions under these three scenarios are 25.092, 16.859, and 17.359 billion tons. In other words, China's emissions reduction targets cannot be easily achieved. In order to keep pace with China's overall mitigation agenda, we put forward the policy recommendations. Through these analyses and discussions, we hope to make contributions to policy stimulation in energy, carbon emissions, and ecological protection.

\section{Introduction}

China's energy issues and carbon emissions have been gaining more and more attention from all over the world. On single year basis, China has become the biggest energy consumer and greenhouse gas emitter in the world and it recorded the world's largest increment in primary energy consumption for fifteen years by 2015 [1]. In 2013, global carbon emissions reached 36 billion tons, while China accounted for about $29 \%$. In 2014, China's total energy consumption reached 4.26 billion TCE (Tons of Standard Coal Equivalent), accounting for about $1 / 4$ of the world's total, and China's coal consumption accounted for more than half of the world's total [2]. China's per capita carbon emissions in 2013 were 7.2 tons/a (Europe's 6.8 tons/a) [3]. According to the results predicted by the IEA (International Energy Agency) and CICERO (Center for International Climate, Environmental Research Oslo), the number of cumulative carbon emissions of China will exceed that of the United States by 2016 [4]. That is to say, China has already become the biggest country in carbon emissions in the world both from the per capita emissions and the cumulative emissions. So, it will have a significant impact on the whole world whether or not China makes viable energy development strategies and carbon reduction plans.

The adjustment and optimization of the primary energy structure will be the core of China's energy strategy in the long run. In the past decades, China has paid more attention to the economic development, ignoring the ecological protection. China obtains most of its energy from coal, the most pollutive fossil fuel. It is believed that the ecological environment deterioration in China is mainly due to its highcarbon energy structure. Fortunately, China has been aware of the seriousness of the problem and actively participating 
TABLE 1: Comparison of the average annual decrease rates of carbon intensity.

\begin{tabular}{lcccc}
\hline USA & EU & UK & GER & CHN \\
\hline $2.3 \%$ & $2.3 \%$ & $3.0 \%$ & $2.5 \%$ & $3.6 \%-4.1 \%$ \\
\hline
\end{tabular}

Note. Carbon intensity is the carbon dioxide emissions per unit of GDP.

TABLE 2: Comparison of per capita carbon emissions (unit: tons/a).

\begin{tabular}{lccc}
\hline USA & UK & GER & CHN \\
\hline 19.5 & 11.3 & 14.1 & $<10$ \\
\hline
\end{tabular}

in international cooperation in energy conservation and emissions reduction.

The international cooperation in the field of climate change has experienced a very tortuous process. In 1896, Swedish scientist Swan Ahrrenius warned that excessive emissions of $\mathrm{CO}_{2}$ would lead to global warming. However, this scientific prediction did not arouse public concern until 1970s. Subsequently, a series of global climate change negotiations were conducted, but the progress was not smooth. In December 2015, China signed the "Paris agreement." In September 2016, at the G20 summit in Hangzhou, China submitted the ratification of the "Paris agreement" to the United Nations. Based on the principle of common but differentiated responsibilities, China has made a commitment to its carbon emissions reduction, which can be summarized as the following three targets.

Target 1. $\mathrm{CO}_{2}$ emissions per unit of GDP will drop $60 \%-65 \%$ by 2030 from 2005 level.

Target 2. $\mathrm{CO}_{2}$ emissions will peak (about 12 billion tons) by 2030.

Target 3. Nonfossil energy will account for $20 \%$ in primary energy by 2030 .

China's emissions reduction commitment means that the average annual decrease rate of carbon intensity must be in the range of $3.6 \%-4.1 \%$ during $2005-2030$. Since 1990, the average annual decrease rates of carbon intensity in USA, EU, UK, and Germany were lower than that in China, which are shown in Table 1.

It is estimated that when the carbon emissions peak, per capita carbon emissions in China will be less than 10 tons and less than those in USA, UK, and Germany, which are shown in Table 2.

All these show that China's emissions reduction targets are laudably ambitious. However, implementation is much more important than commitment. Will China's solemn promises come true? What difficulties may be encountered in the implementation process? These are exactly what we want to discuss in depth in this paper.

A considerable number of studies have been made on China's carbon emissions reduction targets and primary energy structure optimization. Many researchers have studied China's emissions reduction targets [5-11], and different views are in the ongoing debate. The representative views are as follows: Yi et al. believed that China would be able to achieve emissions reduction targets by 2020 without any additional reduction policy [5]. Li et al. believed that in order to achieve emissions reduction targets by 2020 , the Chinese government must be careful to set the target of economic growth and constantly adjust the economic structure and energy structure [11]. Despite the controversy, the researchers gradually have reached a consensus, that is, in order to complete the 2030 carbon emissions reduction targets, China has to optimize the primary energy structure.

Research methods on primary energy structure optimization and carbon reduction can be approximately divided into two categories. One focuses on energy policy and qualitative discussion aspects [12], and the other focuses on quantitative analysis from the aspects of energy substitution, energy intensity, and carbon intensity under some theoretical frameworks such as Environmental Kuznets Curve (EKC), LMDI decomposition, and Kaya factors [13-15]. Scenario analysis method can be used to estimate the future development trend of a research object based on the goals of economic and social development in the future [16-18]. Unlike some usual methods, this research adopts the scenario analysis method and establishes a set of multiobjective optimization models for different scenarios. It studies China's primary energy structure optimization and carbon emissions reduction targets by 2030 from a new perspective.

The remainder of this paper is organized as follows: in Section 2, we analyze China's carbon emissions targets by 2030 without optimization. In Section 3, we construct the optimization models for three scenarios. In Section 4, we display the calculation results and analysis. In the final section, we give the conclusions and policy recommendations.

\section{Analysis of Carbon Reduction Targets without Optimization}

In this section, we want to know whether or not China's emissions reduction targets can be achieved and if the current energy consumption patterns continue.

2.1. Forecasting the Energy Consumption in 2030. A linear regression model is established as follows: $y_{t}=125113+$ $21013.71 \times t(t=1,2, \ldots), R^{2}=0.9888, F=1059.89$, and $P=4.46 \times 10^{-13}<0.05$. Obviously, the linear regression equation is significant. According to the regression equation, the primary energy consumption in 2030 is 7.555 billion TCE.

2.2. Forecasting the Primary Energy Consumption Structure. According to historical data, China's primary energy structure in 2030 can be predicted by the Markov model.

The transition probabilities among these four kinds of primary energies are calculated using OLS method as follows:

$$
\mathbf{P}=\left[\begin{array}{cccc}
0.7973 & 0 & 0.2027 & 0 \\
0 & 0.5244 & 0 & 0.4756 \\
0.0501 & 0 & 0.9395 & 0.0104 \\
0 & 0.2715 & 0 & 0.7285
\end{array}\right]
$$


TABLE 3: China's energy consumption and emissions in 2030 (unit: $\%$, billion TCE, billion tons).

\begin{tabular}{lccccc}
\hline & Coal & Oil & Natural gas & Others & Total \\
\hline ES & 57.86 & 14.91 & 9.60 & 17.63 & 100.00 \\
EC & 4.371 & 1.126 & 0.725 & 1.333 & 7.555 \\
CE & 11.579 & 2.222 & 1.117 & 0.00 & 14.918 \\
\hline
\end{tabular}

On the basis of 2014, let $\mathbf{A}_{2014}$ denote the vector of the primary energy structure in 2014, and the prediction method can be formulated as follows:

$$
\mathbf{A}_{t}=\mathbf{A}_{2014} \times \mathbf{P}^{t-2014} \text {. }
$$

After inputting $\mathbf{A}_{2014}=[17.1,6.2,66.0,10.7]$ and $\mathbf{P}$ into Formula (2), we can obtain the prediction results: $\mathbf{A}_{2030}=$ $[14.91,9.60,57.86,17.63]$. That is to say, the proportions of coal, oil, natural gas, and nonfossil energy are $57.86 \%, 14.91 \%$, $9.60 \%$, and $17.63 \%$ by 2030 , respectively.

2.3. Calculating $\mathrm{CO}_{2}$ Emissions in 2030. We take the average values of the data, released by the domestic and international authoritative organizations (EIA, Japan Institute of Energy Economics, China Academy of Engineering, Global Climate Change Foundation, and the Asian Development Bank), as $\mathrm{CO}_{2}$ emissions coefficients of coal, oil, and natural gas (NG). They are, respectively, 2.6488t/TCE, 1.9727t/TCE, and $1.5407 \mathrm{t} / \mathrm{TCE}$. Then, we calculate the energy structure (ES), energy consumption (EC), and $\mathrm{CO}_{2}$ emissions (CE) in 2030 as shown in Table 3.

China's GDP in 2005 was 18.73 trillion Yuan; energy consumption was 2.36 billion TCE, and the shares of coal, oil, natural gas, and nonfossil energy were $70.8 \%, 19.8 \%$, $2.6 \%$, and $6.8 \%$, respectively. So, we can conclude that China's carbon emissions in 2005 were $1.48 \mathrm{Gt}$, equivalent to 5.442 billion tons of $\mathrm{CO}_{2}$ emissions, which are close to the results calculated by Sun et al. $[19,20]$. Thus, the intensity of $\mathrm{CO}_{2}$ in 2005 was 2.9055 tons per ten thousand Yuan.

\subsection{Analyzing the Fulfillment of the Three Targets}

Target 1. $\mathrm{CO}_{2}$ emissions per unit of GDP will drop 60\%-65\% from 2005 level by 2030. Assume that the average annual growth rate of GDP is $r$. Let $149.18 /\left(\mathrm{GDP}_{2015} \times(1+r)^{15}\right)=$ $2.9055 \times 40 \%$; then $r=4.36 \%$. That is to say, it is impossible to achieve this predetermined carbon intensity target, if the average annual growth rate of GDP is less than $4.36 \%$ from 2015 to 2030 (if the $\mathrm{CO}_{2}$ intensity drops 65\%, then the corresponding average annual growth rate of GDP is $5.29 \%$ ). Given the weak global economic recovery, it is still more challenging to achieve Target 1 .

Target 2. $\mathrm{CO}_{2}$ emissions will peak (about 12 billion tons) by 2030. In the absence of optimization, the calculation results show that China's $\mathrm{CO}_{2}$ emissions will reach 14.918 billion tons by 2030, far exceeding the upper limit of China's emissions. So, target 2 cannot be achieved.

Target 3. Nonfossil energy will account for $20 \%$ in primary energy by 2030. In the absence of optimization, the nonfossil energy accounts for $17.63 \%$ and does not achieve the goal of $20 \%$ according to the forecast results.

From the analysis above, we can draw a conclusion that China's scheduled emissions reduction targets can be hardly achieved if the current energy consumption patterns are not changed.

\section{Modeling under Three Optimization Scenarios}

In order to reach the targets, we have to optimize the primary energy structure. We establish the optimization models under three scenarios. The general principle of optimization is to reduce energy consumption and $\mathrm{CO}_{2}$ emissions while maintaining the sustainable economic growth. Therefore, we set three goals, namely, economic growth maximization, energy consumption minimization, and $\mathrm{CO}_{2}$ emissions minimization.

3.1. Three Goals. Let $x_{i}(i=1,2, \ldots, m)$ denote the added value of the $i$ th industry; then the whole GDP can be expressed as $\sum_{i=1}^{m} x_{i}$, and the goal of economic growth can be expressed as $\max \sum_{i=1}^{m} x_{i}$. Let $e_{i}(i=1,2, \ldots, m)$ denote the energy intensity of the $i$ th industry and $U_{E}$ denote living energy consumption; then total energy consumption can be expressed as $\sum_{i=1}^{m} e_{i} x_{i}+U_{E}$, and the goal of energy consumption can be expressed as $\min \left(\sum_{i=1}^{m} e_{i} x_{i}+U_{E}\right)$. Let $s_{j}(j=1,2, \ldots, n)$ denote the proportion of the $j$ th energy in primary energy and $\omega_{j}$ denote the $\mathrm{CO}_{2}$ emissions coefficient of the $j$ th energy; then the $\mathrm{CO}_{2}$ emissions coefficient is $\sum_{j=1}^{n} s_{j} \omega_{j}$, and the $\mathrm{CO}_{2}$ emissions goal can be expressed as $\min \left(\sum_{i=1}^{m} e_{i} x_{i}+U_{E}\right)\left(\sum_{j=1}^{n} s_{j} \omega_{j}\right)$.

3.2. Constraint from GDP Growth. Suppose $Q_{0}$ indicates the base period GDP, $T$ indicates the predicted time span, and $r$ indicates the average annual growth rate of GDP; then $\sum_{i=1}^{m} x_{i} \geq Q_{0}(1+r)^{T}$. Let $d_{1}^{+}$and $d_{1}^{-}$denote the positive and negative deviation variables between the actual and the predicted values of the final period of GDP; then $\sum_{i=1}^{m} x_{i}+$ $d_{1}^{-}-d_{1}^{+}=Q_{0}(1+r)^{T}$.

3.3. Constraint from Energy Consumption. Assume that $P_{0 e}$ represents the base period energy intensity and $R_{e}$ represents the energy intensity decrease rate during the analysis period; then $\sum_{i=1}^{m} e_{i} x_{i}+U_{E} \leq P_{0 e}\left(1-R_{e}\right) \sum_{i=1}^{m} x_{i}$. Assume that $d_{2}^{+}$and $d_{2}^{-}$, respectively, represent the positive and negative deviation variables between the actual and the predicted values of the final period energy consumption; then $\sum_{i=1}^{m} e_{i} x_{i}+U_{E}+d_{2}^{-}-$ $d_{2}^{+}=P_{0 e}\left(1-R_{e}\right) \sum_{i=1}^{m} x_{i}$.

3.4. Constraint from $\mathrm{CO}_{2}$ Emissions. Let $P_{0 c}$ denote the base period $\mathrm{CO}_{2}$ emissions intensity and $R_{c}$ denote the $\mathrm{CO}_{2}$ emissions intensity decrease rate during the analysis period; 
then $\left(\sum_{i=1}^{m} e_{i} x_{i}+U_{E}\right)\left(\sum_{j=1}^{n} s_{j} \omega_{j}\right) \leq P_{0 c}\left(1-R_{c}\right) \sum_{i=1}^{m} x_{i}$. Let $d_{2}^{+}$and $d_{2}^{-}$, respectively, denote the positive and negative deviation variables between the actual and the predicted values of the final period $\mathrm{CO}_{2}$ emissions; then $\left(\sum_{i=1}^{m} e_{i} x_{i}+\right.$ $\left.U_{E}\right)\left(\sum_{j=1}^{n} s_{j} \omega_{j}\right)+d_{3}^{-}-d_{3}^{+}=P_{0 c}\left(1-R_{c}\right) \sum_{i=1}^{m} x_{i}$.

Scenario 1 (energy structure optimization).

$\min$

$$
\begin{aligned}
& Z=P_{1} d_{1}^{-}+P_{2} d_{2}^{+}+P_{3} d_{3}^{+} \\
& \sum_{i=1}^{m} x_{i}+d_{1}^{-}-d_{1}^{+}=Q_{0}(1+r)^{T} \\
& \sum_{i=1}^{m} e_{i} x_{i}+U_{E}+d_{2}^{-}-d_{2}^{+}=P_{0 e}\left(1-R_{e}\right) \sum_{i=1}^{m} x_{i} \\
& \left(\sum_{i=1}^{m} e_{i} x_{i}+U_{E}\right)\left(\sum_{j=1}^{n} s_{j} \omega_{j}\right)+d_{3}^{-}-d_{3}^{+} \\
& =P_{0 c}\left(1-R_{c}\right) \sum_{i=1}^{m} x_{i} \\
& s_{j}^{-} \leq s_{j} \leq s_{j}^{+}, \quad \sum_{j=1}^{n} s_{j}=1, j=1,2, \ldots, n, \\
& x_{i 0}\left(1+r_{i}^{-}\right)^{T} \leq x_{i} \leq x_{i 0}\left(1+r_{i}^{+}\right)^{T}, \\
& d_{1}^{-}, d_{1}^{+}, d_{2}^{-}, d_{2}^{+}, d_{3}^{-}, d_{3}^{+} \geq 0, \quad i=1,2, \ldots, m,
\end{aligned}
$$

where, $s_{j}^{-}, s_{j}^{+}$, respectively, represent the lower and the upper share limits of the $j$ th energy in the primary energy structure, and $x_{i 0}, r_{i}^{-}, r_{i}^{+}$, respectively, represent the added value of the $i$ th industry in base period and the lower and the upper limits of the average annual growth rate during the analysis period.

Scenario 2 (energy intensity optimization).

$$
\begin{array}{ll}
\min & Z=P_{1} d_{1}^{-}+P_{2} d_{2}^{+}+P_{3} d_{3}^{+} \\
& \sum_{i=1}^{m} x_{i}+d_{1}^{-}-d_{1}^{+}=Q_{0}(1+r)^{T} \\
& \sum_{i=1}^{m} e_{i} x_{i}+U_{E}+d_{2}^{-}-d_{2}^{+}=P_{0 e}\left(1-R_{e}\right) \sum_{i=1}^{m} x_{i} \\
& \left(\sum_{i=1}^{m} e_{i} x_{i}+U_{E}\right)\left(\sum_{j=1}^{n} s_{j} \omega_{j}\right)+d_{3}^{-}-d_{3}^{+} \\
& =P_{0 c}\left(1-R_{c}\right) \sum_{i=1}^{m} x_{i} \\
e_{i}^{-} \leq e_{i} \leq e_{i}^{+}, \quad i=1,2, \ldots, m
\end{array}
$$

$$
\begin{aligned}
x_{i 0}\left(1+r_{i}^{-}\right)^{T} \leq x_{i} \leq x_{i 0}\left(1+r_{i}^{+}\right)^{T} & \\
& \\
& i=1,2, \ldots, m
\end{aligned}
$$$$
d_{1}^{-}, d_{1}^{+}, d_{2}^{-}, d_{2}^{+}, d_{3}^{-}, d_{3}^{+} \geq 0
$$

where $e_{i}$ represents the energy intensity of the $i$ th industry, and the other parameters are the same as the model above.

Scenario 3 (energy structure-intensity optimization).

$$
\begin{aligned}
& \min \quad Z=P_{1} d_{1}^{-}+P_{2} d_{2}^{+}+P_{3} d_{3}^{+} \\
& \sum_{i=1}^{m} x_{i}+d_{1}^{-}-d_{1}^{+}=Q_{0}(1+r)^{T} \\
& \sum_{i=1}^{m} e_{i} x_{i}+U_{E}+d_{2}^{-}-d_{2}^{+}=P_{0 e}\left(1-R_{e}\right) \sum_{i=1}^{m} x_{i} \\
& \left(\sum_{i=1}^{m} e_{i} x_{i}+U_{E}\right)\left(\sum_{j=1}^{n} s_{j} \omega_{j}\right)+d_{3}^{-}-d_{3}^{+} \\
& =P_{0 c}\left(1-R_{c}\right) \sum_{i=1}^{m} x_{i} \\
& e_{i}^{-} \leq e_{i} \leq e_{i}^{+}, \quad i=1,2, \ldots, m \\
& s_{j}^{-} \leq s_{j} \leq s_{j}^{+}, \quad \sum_{j=1}^{n} s_{j}=1, j=1,2, \ldots, n \\
& x_{i 0}\left(1+r_{i}^{-}\right)^{T} \leq x_{i} \leq x_{i 0}\left(1+r_{i}^{+}\right)^{T}, \\
& d_{1}^{-}, d_{1}^{+}, d_{2}^{-}, d_{2}^{+}, d_{3}^{-}, d_{3}^{+} \geq 0,
\end{aligned}
$$

where the parameters are the same as the models above.

\section{Results and Analysis}

4.1. Data Selections and Preliminary Analysis. Data used in this study are available in the "China Statistical Yearbook" and "China Energy Statistical Yearbook," which were released by the China National Bureau of Statistics. This paper divides all industries into six sections, namely, "Agriculture, Forestry, Animal Husbandry, and Fishery (AFAF)," "industry (IN)," "Construction Industry (CI)," "transportation, warehousing, and postal service (TWPS)," "Wholesale and Retail, Accommodation, and Catering (WRAC)," and "Others." The data, such as the added values and energy consumption of the six sections, can be obtained from the "China Statistical Yearbook" and "China Energy Statistical Yearbook," and then the energy intensities can be calculated. The changing trend of the energy intensity of each section is shown in Figure 1 (unit: TCE $/ 10^{4}$ Yuan).

The "Total" in this figure is the total energy intensity. From Figure 1 we can see the energy intensities basically show gradual downward trends, except "Others." The "Total" is 


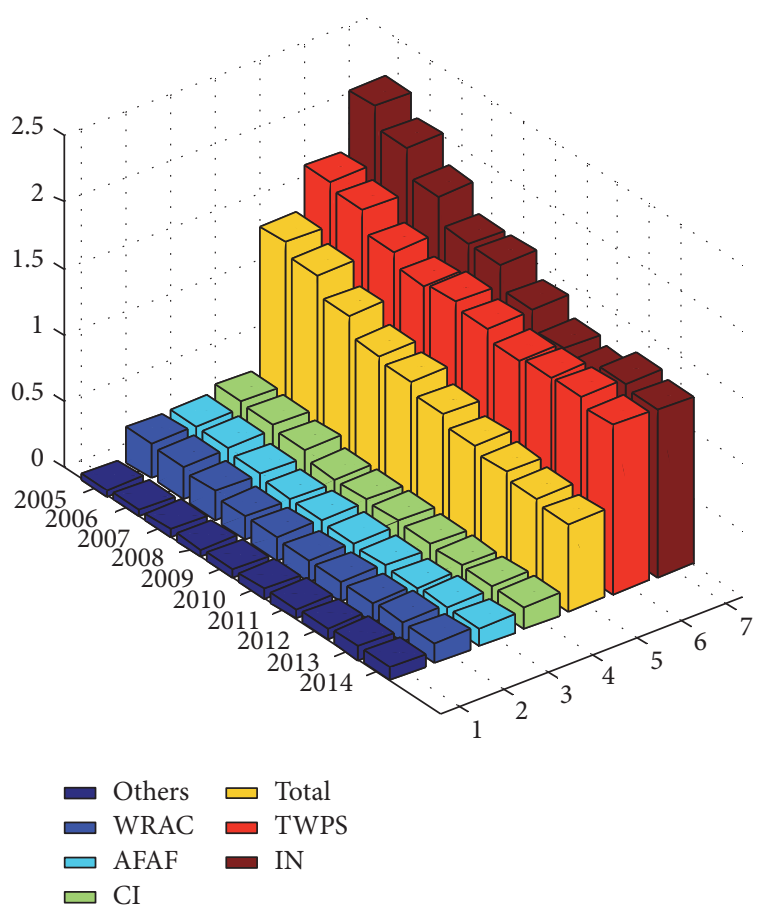

FIGURE 1: Changing trends of the energy intensities.

pulled high mainly by "IN" energy intensity and "TWPS" energy intensity. The decreasing trends of energy intensities are slowing down year by year, but the increasing trend appears in a linear increase. Decrease rates of "AFAF," "CI," and "WRAC" are fluctuating, and the energy intensity of "IN" has even bounced back, which indicates that the further decline potential in the energy intensities has been very limited. Energy intensity of "Others" increases basically at an annual growth rate of about $10 \%$.

In order to assist the following optimization work, we estimate the range of energy intensity of each section in 2030 on the basis of 2014. The GM $(1,1)$ model is established to predict the energy intensity of each section in 2030, and the forecast interval is shown in Table 4, considering the fluctuation of $\pm 20 \%$.

Under the background of the global economic downturn, China's annual growth rate of GDP shows a downtrend on a yearly basis. Figure 2 shows the changing trends of GDP growth rates in these sections.

From Figure 2, we can see that China's economic growth appeared inflection point in 2009, and GDP growth rate was at a local minimum. Why? That is because the financial crisis in 2008 exerted negative impacts on China's economy, which was reflected in 2009. China's economy rebounded in 2010 but soon entered a rapid descent channel. China's economic growth rate fell to $6.9 \%$ in 2015 , which was the lowest point since 1990 and maintained $6.7 \%$ in the first three-quarters of 2016. At present, there is no sign to reverse this trend.

4.2. Calculation Results and Analysis. Through the optimization models mentioned above, we calculated GDP, energy consumption, total decreases in energy intensity, $\mathrm{CO}_{2}$

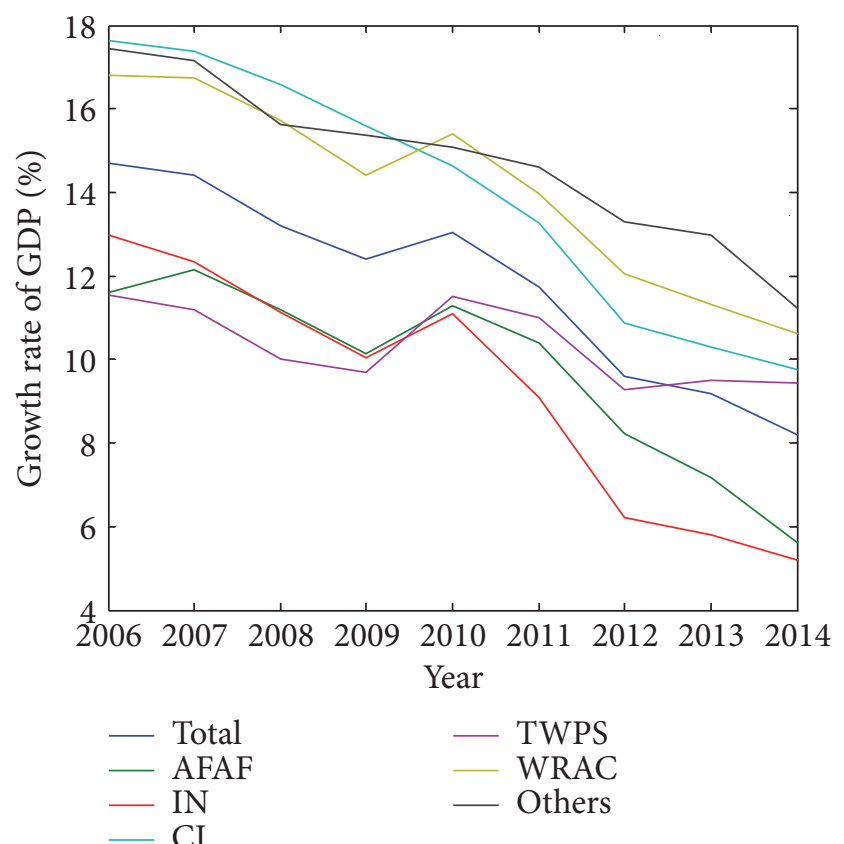

FIGURE 2: The changing trends of GDP growth rate.

TABLE 4: The estimate ranges of energy intensity (unit: TCE/ $10^{4}$ Yuan).

\begin{tabular}{lcc}
\hline & Energy intensity in 2014 & Estimate ranges in 2030 \\
\hline Total & 0.6612 & $(0.2026,0.3038)$ \\
AFAF & 0.1345 & $(0.0943,0.1415)$ \\
IN & 1.2644 & $(1.1681,1.7521)$ \\
CI & 0.1675 & $(0.1026,0.1538)$ \\
TWPS & 1.2749 & $(0.9386,1.4078)$ \\
WRAC & 0.1478 & $(0.1371,0.2057)$ \\
Others & 0.0989 & $(0.3914,0.5872)$ \\
\hline
\end{tabular}

emissions, total decreases in $\mathrm{CO}_{2}$ emissions, the average energy intensity, and energy structure under each scenario. Considering that the proportion of coal should drop to about $50 \%$ and the proportion of nonfossil energy should reach about $20 \%$ in 2030 according to China's power plan, we suppose coal and nonfossil energy account for 50\% and $20 \%$, respectively, in the energy intensity optimization model. The optimization results under the three scenarios are presented in Table 5.

Table 5 demonstrates that, under the three scenarios, the total amounts of GDP are 151.80 trillion Yuan in 2030 based on the highest priority of economic growth. However, energy consumption is very different. Scenario 1 is 13.639 billion TCE, and Scenarios 2 and 3 are both 9.436 billion TCE. The total decreases in energy intensity reach $35.61 \%, 55.45 \%$, and $55.45 \%$, and the total decreases in $\mathrm{CO}_{2}$ intensity reach $43.11 \%$, $61.78 \%$, and $61.78 \%$, respectively. In terms of energy structure optimization, results of Scenarios 1 and 3 are the same, and the proportions of coal, oil, natural gas, and nonfossil energy reach $17.89 \%, 11.52 \%, 49.43 \%$, and $21.16 \%$, respectively. $\mathrm{CO}_{2}$ 
TABLE 5: The optimization results under the three scenarios.

\begin{tabular}{lcccccc}
\hline & $\begin{array}{c}\text { GDP } \\
\text { (trillion Yuan) }\end{array}$ & $\begin{array}{c}\mathrm{EC} \\
\text { (billion TCE) }\end{array}$ & $\begin{array}{c}\mathrm{RE} \\
(\%)\end{array}$ & $\begin{array}{c}\mathrm{RC} \\
(\%)\end{array}$ & $\begin{array}{c}\mathrm{ES} \\
(\%)\end{array}$ & $\begin{array}{c}\mathrm{CO}_{2} \mathrm{E} \\
\text { (billion tons) }\end{array}$ \\
\hline Scenario 1 & 151.80 & 13.639 & 35.61 & 43.11 & $(49.43,17.89,11.52,21.16)$ & 25.092 \\
Scenario 2 & 151.80 & 9.436 & 55.45 & 61.78 & $(50.00,0.00,30.00,20.00)$ & 16.859 \\
Scenario 3 & 151.80 & 9.436 & 55.45 & 60.64 & $(49.43,17.89,11.52,21.16)$ & 17.359 \\
\hline
\end{tabular}

Note. GDP: gross domestic product; EC: energy consumption; RE: total decreases in energy intensity; RC: total decreases in $\mathrm{CO}_{2}$ intensity; ES: energy structure; and $\mathrm{CO}_{2} \mathrm{E}: \mathrm{CO}_{2}$ emissions.

emissions under the three scenarios are 25.092, 16.859, and 17.359 billion tons.

Target 1. $\mathrm{CO}_{2}$ emissions per unit of GDP will drop 60\%-65\% by 2030 from 2005 level. The findings show that only in Scenarios 2 and 3 can China fulfill the commitment of the carbon emissions reduction. The total decreases in $\mathrm{CO}_{2}$ intensity reach $61.78 \%$ and $60.64 \%$, respectively, neither of which gets to the upper limit of $65 \%$. In Scenario 1, the aggregate decrease in $\mathrm{CO}_{2}$ intensity is only $43.11 \%$, far below the lower limit of $60 \%$.

Target 2. CO2 emissions will peak (about 12 billion tons) by 2030 . The findings show that the peak goal of carbon emissions is not achieved under these three scenarios. The highest CO2 emission reaches 25.092 billion tons, and the lowest emission reaches 16.859 billion tons.

Target 3. Nonfossil energy will account for $20 \%$ in primary energy by 2030. The findings show that the target can be achieved under the three scenarios, and, furthermore, it runs up to $21.16 \%$ under Scenarios 1 and 3.

\section{Conclusions and Recommendations}

This paper gives the analysis of China's emissions reduction targets by 2030. From the findings, we can draw the following conclusions.

Without artificial intervention, the proportions of coal, oil, natural gas, and nonfossil energy are 57.86\%, $14.91 \%$, $9.60 \%$, and $17.63 \%$ by 2030 , respectively. Energy consumption will reach 7.555 billion TCE, and $\mathrm{CO}_{2}$ emissions will reach 14.918 billion tons. If the average annual growth rate of GDP is less than $4.36 \%$, then the predetermined carbon intensity target cannot be achieved. If the current emission trends continue, then the $\mathrm{CO}_{2}$ peak control objective cannot be achieved. In addition, the target that nonfossil energy accounts for $20 \%$ in primary energy cannot be achieved.

In the context of optimization, the proportions of coal, oil, natural gas, and nonfossil energy reach $17.89 \%, 11.52 \%$, $49.43 \%$, and $21.16 \%$ by 2030 in Scenarios 1 and 3, respectively. Energy consumption under Scenario 1 is 13.639 billion TCE, and in Scenarios 2 and 3 is 9.436 billion TCE for both. $\mathrm{CO}_{2}$ emissions under the three scenarios are 25.092, 16.859, and 17.359 billion tons. $\mathrm{CO}_{2}$ intensity targets will be fulfilled under Scenarios 2 and 3. But the total decrease in $\mathrm{CO}_{2}$ intensity under Scenario 1 is only $43.11 \%$. The target that nonfossil energy accounts for $20 \%$ in primary energy can be achieved under all three scenarios.
The results under the nonoptimization and the three optimization scenarios all show that China's carbon emissions reductions targets, unlike those some researchers claimed, cannot be achieved easily. On the contrary, China's $\mathrm{CO}_{2}$ emissions will be more than 12 billion tons, even under the three optimization scenarios.

So, why does target 2 is not to be fulfilled? After indepth analysis, we find that the reason lies in the high energy consumption of China's economic structure. In the six sections, the energy intensities of "IN" (industry) and "TWPS" (transportation, warehousing, and postal services) will still be very high in 2030. Therefore, in order to attain the targets of the carbon emissions reductions, China should not only adjust the energy structure, but also make great efforts to adjust the economic structure synchronously. Under the background of China's economic development entering into the new normal and the world's energy supply pattern undergoing major changes, we makes some policy recommendations to provide reference for China's relevant policy makers.

(1) Building the modern energy system. The Chinese government should build a clean, low-carbon, safe, and efficient modern energy system as soon as possible. The important task is to control the excessive consumption of coal, since the high proportion of coal is the main reason for China's excessive emissions of $\mathrm{CO}_{2}$. According to the study on greenhouse gas inventory in China, in the electric power industry, $\mathrm{CO}_{2}$ emissions from burning one ton of coal are $23 \%-31 \%$ more than fuel oil and $70 \%-80 \%$ more than natural gas with the same calorific value. It is recommended to establish a dual control system of carbon emissions and emissions intensity before 2020 and introduce strict measures to control the total coal consumption, so as to curb the excessive growth of energy consumption throughout the country. During the period of 2020-2030, Chinese government should strengthen the comprehensive implementation of carbon emissions control system, set the fossil energy consumption control targets, take strict measures, and promote high-carbon fossil energies (coal and oil) consumption to peak before 2030. In addition, China should also fully implement the coal replacement policy. Therefore, China should vigorously develop nonfossil energy sources, including hydropower, wind power, photovoltaic power, nuclear power, and biomass energy. China should 
introduce more policies to support the development of nonfossil energy industry and constantly optimize the energy structure.

(2) Continuing to strongly promote the adjustment of industrial structure. In China, many industries have serious overcapacity. For example, the iron and steel industry, cement industry, and glass industry, all have serious excess capacity, wasting a huge amount of energy and emitting a huge amount of greenhouse gases. The adjustment of industrial structure includes two aspects, the rationalization of industrial structure and the upgrading of industrial structure. Rationalization of industrial structure needs the Chinese government to accelerate the elimination of backward production capacities and control the scale of high energy-consuming industries strictly by controlling the increments and reducing the stock. The upgrading of industrial structure requires the Chinese government to increase technological innovation, upgrade the industrial structure, and promote the industries with high added values and low energy consumption as soon as possible.

(3) Strengthening international energy cooperation. In order to support China's energy structure optimization, the Chinese government needs to strengthen energy international cooperation. It is necessary to increase the use of oil and natural gas after reducing the use of coal, considering that the nonfossil energy can only partially fill the ullage. International energy cooperation can ensure the supply of oil and natural gas and reduce the risk in energy supply. China, in particular, should strengthen its oil and gas trades with Russia and Central Asia in order to reduce the risk in energy transportation by sea.

(4) Speeding up the science and technology innovation related to energy. Science and technology determine and create the future of energy. In recent years, some major countries have adopted a series of laws and policies to speed up the innovation of energy technology. Science and technology innovation has not been treated as the core of energy policy system in China. From the national perspective, China has not yet developed a comprehensive strategy and made a technology roadmap for its future energy technology innovation. We recommend that Chinese government should intensify its efforts in some science and technology innovations, such as the coal harmless mining technology, deep-sea oil and gas development technology, clean and efficient utilization of coal technology, carbon capture, utilization and storage technology, advanced nuclear technology, efficient utilization of solar energy technology, largescale wind power technology, hydrogen and fuel cell technology, biomass, ocean, geothermal energy utilization technology, energy saving and efficiency improving technology.

\section{Conflicts of Interest}

The authors declare that there are no conflicts of interest regarding the publication of this paper.

\section{Acknowledgments}

This paper was supported by the Fundamental Research Funds for the Central Universities (2015MS150, 2015ZD32).

\section{References}

[1] BP, "Statistical review of world energy," http://www.bp.com/en/ global/corporate/energy-economics/statistical-review-of-worldenergy/2015-in-review.html.

[2] Scientific American, "Fossil Fuel Use Continues to Rise," https:// www.scientificamerican.com/article/fossil-fuel-use-continuesto-rise/.

[3] D. Qiang, W. Ning, and C. Lei, "Forecasting China's per capita carbon emissions under a new three-step economic development strategy," Journal of Resources and Ecology, vol. 6, no. 5, pp. 318-323, 2015.

[4] Daily China, Russia and China can build pipeline by $2020-$ IEA, http://ua-energy.org/en/post/14600.

[5] B.-W. Yi, J.-H. Xu, and Y. Fan, "Determining factors and diverse scenarios of $\mathrm{CO}_{2}$ emissions intensity reduction to achieve the 40-45\% target by 2020 in China-a historical and prospective analysis for the period 2005-2020," Journal of Cleaner Production, vol. 122, pp. 87-101, 2015.

[6] J. M. Cansino, R. Román, and J. M. Rueda-Cantuche, "Will China comply with its 2020 carbon intensity commitment?" Environmental Science and Policy, vol. 47, pp. 108-117, 2015.

[7] D. I. Stern and F. Jotzo, "How ambitious are China and India's emissions intensity targets?" Energy Policy, vol. 38, no. 11, pp. 6776-6783, 2010.

[8] L. Yang, J. Wang, and J. Shi, "Can China meet its 2020 economic growth and carbon emissions reduction targets?" Journal of Cleaner Production, vol. 142, part 2, pp. 993-1001, 2017.

[9] J.-L. Jiao, Y.-Y. Qi, Q. Cao, L.-C. Liu, and Q.-M. Liang, "China’s targets for reducing the intensity of $\mathrm{CO}_{2}$ emissions by 2020," Energy Strategy Reviews, vol. 2, no. 2, pp. 176-181, 2013.

[10] L. Zhou, X. Zhang, T. Qi, J. He, and X. Luo, "Regional disaggregation of China's national carbon intensity reduction target by reduction pathway analysis," Energy for Sustainable Development, vol. 23, no. 1, pp. 25-31, 2014.

[11] H.-Q. Li, L.-M. Wang, L. Shen, and F.-N. Chen, "Study of the potential of low carbon energy development and its contribution to realize the reduction target of carbon intensity in China," Energy Policy, vol. 41, pp. 393-401, 2012.

[12] L. C. Hunt and Y. Ninomiya, "Primary energy demand in Japan: an empirical analysis of long-term trends and future CO2 emissions," Energy Policy, vol. 33, no. 11, pp. 1409-1424, 2005.

[13] X. D. Diao, S. X. Zeng, C. M. Tam, and V. W. Y. Tam, "EKC analysis for studying economic growth and environmental quality: a case study in China," Journal of Cleaner Production, vol. 17, no. 5, pp. 541-548, 2009.

[14] Q. Liu, S. Liu, and L. Kong, "Decomposition and decoupling analysis of energy-related carbon emissions from China manufacturing," Mathematical Problems in Engineering, vol. 2015, Article ID 268286, 9 pages, 2015. 
[15] W. Li and Q.-X. Ou, "Decomposition of China's carbon emissions intensity from 1995 to 2010: an extended kaya identity," Mathematical Problems in Engineering, vol. 2013, Article ID 973074, 7 pages, 2013.

[16] H. Hao, Z. Liu, F. Zhao, W. Li, and W. Hang, "Scenario analysis of energy consumption and greenhouse gas emissions from China's passenger vehicles," Energy, vol. 91, pp. 151-159, 2015.

[17] S. T. Tan, H. Hashim, J. S. Lim, W. S. Ho, C. T. Lee, and J. Yan, "Energy and emissions benefits of renewable energy derived from municipal solid waste: analysis of a low carbon scenario in Malaysia," Applied Energy, vol. 136, pp. 797-804, 2014.

[18] S. Syri, A. Lehtilä, T. Ekholm, I. Savolainen, H. Holttinen, and E. Peltola, "Global energy and emissions scenarios for effective climate change mitigation-deterministic and stochastic scenarios with the TIAM model," International Journal of Greenhouse Gas Control, vol. 2, no. 2, pp. 274-285, 2008.

[19] J. W. Sun, R. Q. Zhao, X. J. Huang et al., "Research on carbon emission estimation and factor decomposition of China from 1995 to 2005," Journal of Natural Resources, no. 8, pp. 1284-1295, 2010.

[20] Q. Liu, X. Zhuang, K. J. Jiang et al., "Energy and carbon embodied in main exporting goods of China," China Industrial Economy, no. 8, pp. 46-55, 2008. 


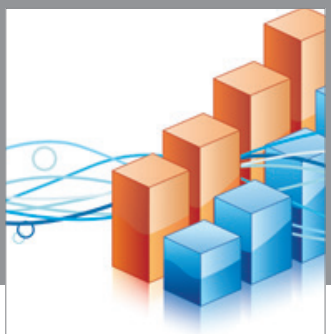

Advances in

Operations Research

vatem alat4

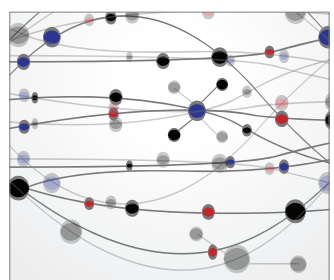

\section{The Scientific} World Journal
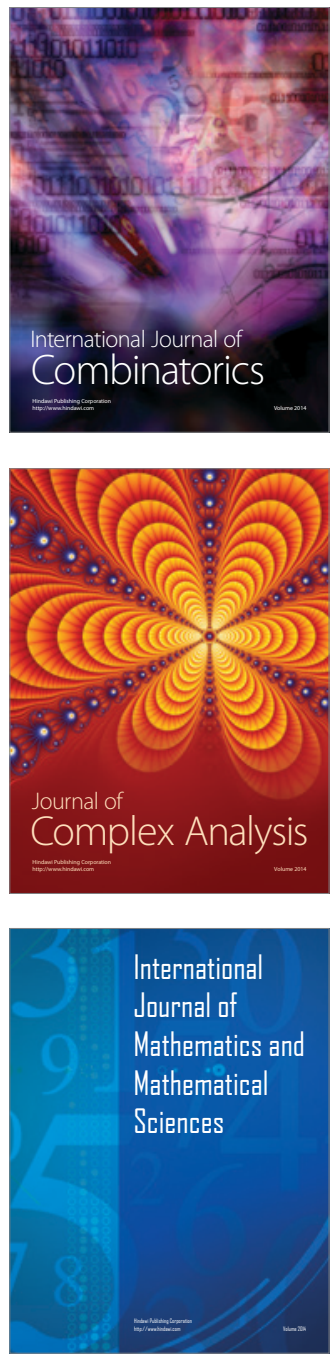
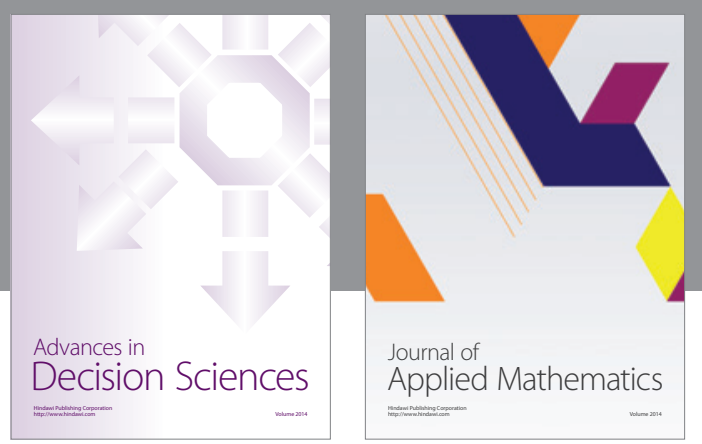

Algebra

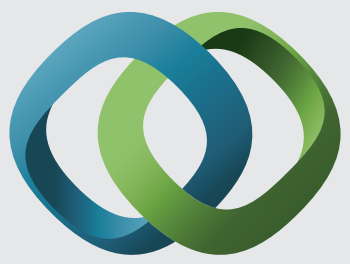

\section{Hindawi}

Submit your manuscripts at

https://www.hindawi.com
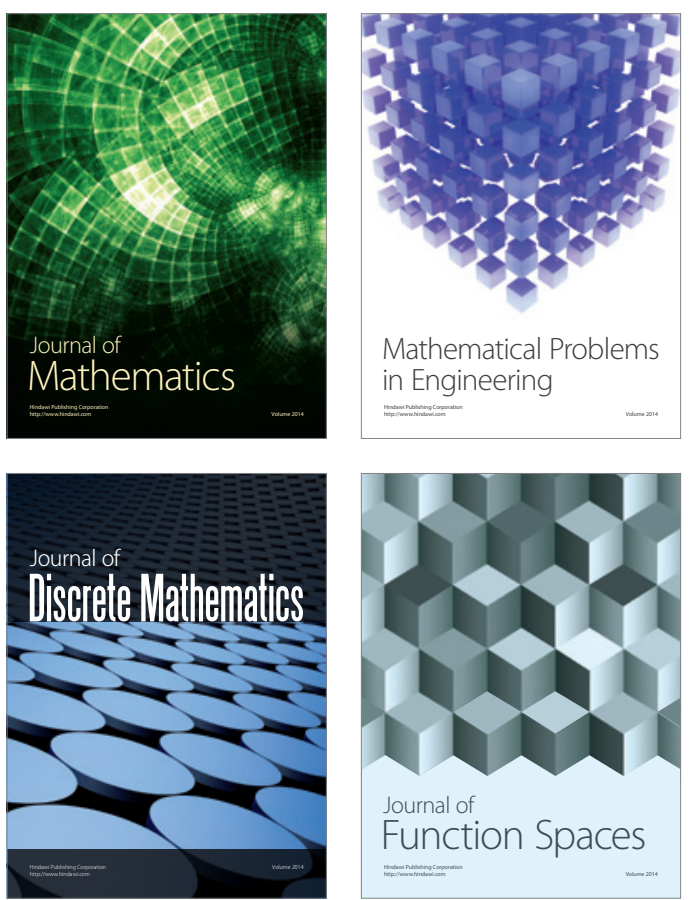

Mathematical Problems in Engineering
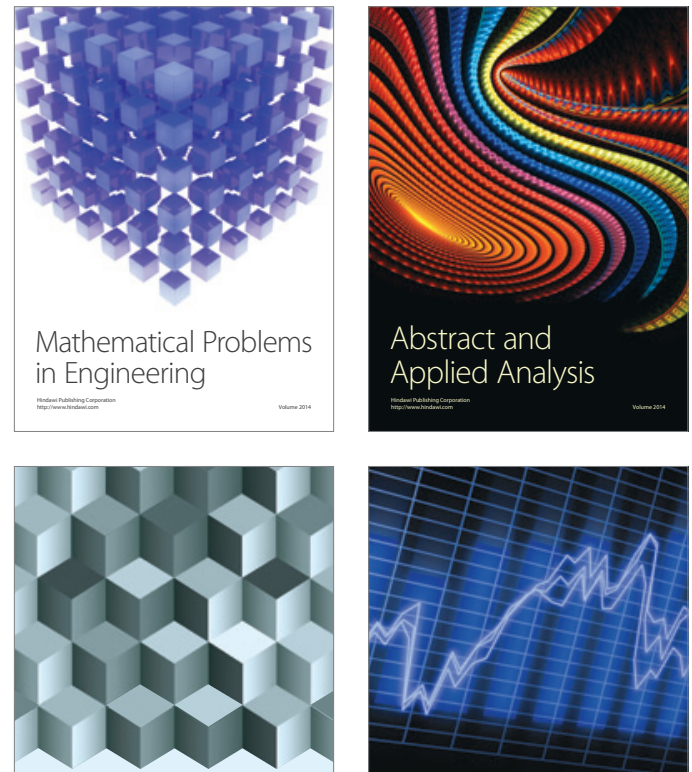

Journal of

Function Spaces

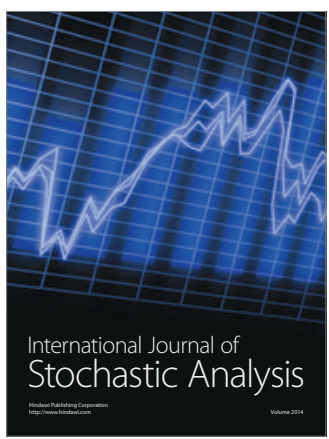

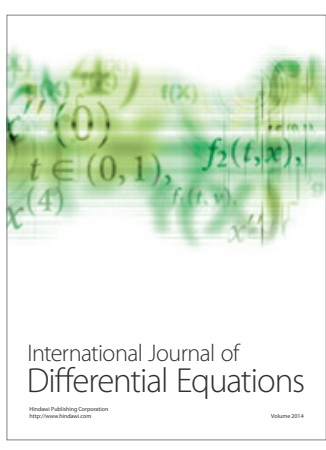
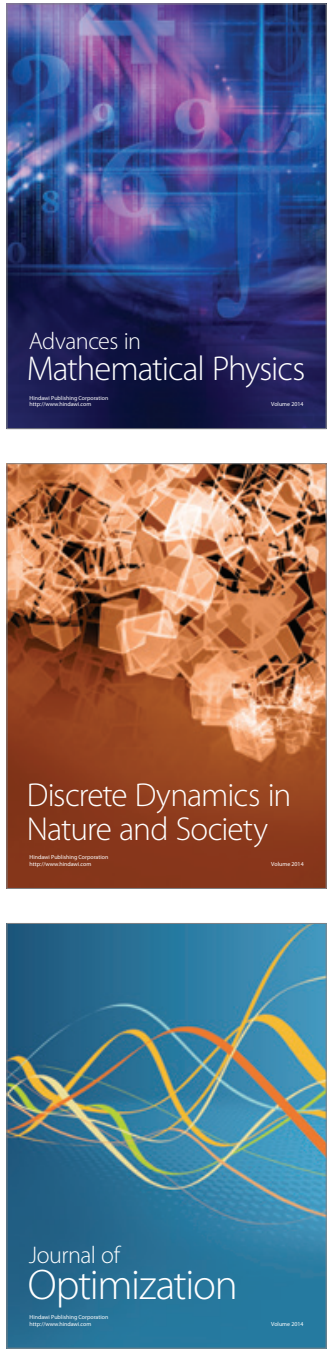